Produto\&Produção, vol. 9, n. 1, p. 03-13, fev. 2008

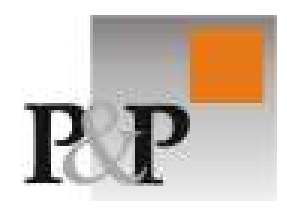

\title{
Aplicação do GRAFCET na redução do retrabalho de uma linha de pintura automotiva
}

\author{
Luciano de Lima Lopes, M.Eng. \\ Francisco José Grandinetti, Dr. \\ grandi@unitau.br
}

Marcio Abud Marcelino, Dr.

abud@feg.unesp.br

$\mathrm{Na}$ área de pintura, em geral, o maior problema encontrado no processo de aplicação é a quantidade de impurezas sobre a superfície de trabalho. As empresas fazem muitos investimentos para eliminar este problema que, em muitas vezes, é invisível ao olho humano. Inicialmente, procurou-se mapear e identificar as áreas com maior sujidade na planta estudada. Encontraram-se cabines com boas condições para aplicação, porém, a parte exterior da cabine possuía outras fontes contamináveis, como o próprio ar (devido ao sistema de filtragem) e as poeiras, ambas geradas pelo processo. Este trabalho apresenta um sistema de filtragem de ar na área de pintura, o sistema de limpeza das carrocerias e a proposta de implementação de uma cortina de ar automatizada para limpeza das carrocerias na área de pintura. Nesta cortina, desenvolveu-se um sistema de automação em que é possível gerar a trajetória para cada tipo de veículo, levando em consideração a sua silhueta. O programa para o funcionamento da cortina foi implementado em linguagem "Ladder"; o programa para o cálculo da trajetória foi implementado em linguagem "C" e a descrição do funcionamento foi realizado utilizando o diagrama de blocos GRAFCET, o que permitiu a verificação de cada etapa do funcionamento da cortina. Sensores ópticos são utilizados para garantir a segurança do sistema quando este estiver em funcionamento. Ensaios, realizados com simulação de limpeza em placas, comprovaram a eficiência do sistema.

Palavras-chave: cortina de ar; limpeza; automatizada; Ladder; GRAFCET

In the painting area in general, the problem found in the application process is the tyred impurities on the work surface. The companies make many investments to eliminate this problem that, in many times, is invisible to the human eye. Initially, it was looked to map and to identify the areas with bigger dirtiness in the studied plant. Good cabins with condition for application had met, the external part of the cabin possesses other pollutants sources, as the own air (had to the filtering system) and the dusts generated for the process. This work presents a system of air filtering in the painting area, the system of cleanness of the trucks and the proposal of implementation of a air curtain automated for cleanness of the trucks in the painting area. In this curtain, was developed a system of automation where possible to generate the trajectory for each type of vehicle, taking in consideration its silhouette. The program for the functioning of the curtain was implemented in language to Ladder, the program for calculate of the trajectory was implemented in language "C" and the description of the functioning was carried through, using the diagram of Grafcet blocks, that it allowed verification of each stage of the functioning of the curtain. Through the use optical sensors to guarantee system security, when this will be in functioning. Assays, carried through with simulation of cleanness in plates, they had proven the efficiency of the system.

Keywords: curtain air; cleanness; automated; Ladder; GRAFCET 


\section{Introdução}

Com a globalização, aumentou o nível de exigência da qualidade dos produtos comercializados entre os países. No setor automobilístico, com o crescimento do mercado, as indústrias aumentaram o nível de automação de suas plantas. O processo de pintura dos veículos está sendo feito automaticamente por robôs e máquinas de pintura. Com este alto índice de automação, necessita-se de um processo de limpeza das carrocerias também automatizado, pois, na área de pintura, grande parte dos "retrabalhos" é gerada pela "sujidade" depositada nas carrocerias. Essa sujeira é proveniente de diversas fontes:

- filtros mal dimensionados;

- limpeza deficiente das carrocerias;

- aspectos comportamentais dos pintores;

- balanceamento das cabines etc.

A Tabela 1 e a Figura 1 ilustram a evolução do índice de sujeira em relação à quantidade de defeitos gerados no processo de pintura.

Tabela 1 - Sujeira x Índice de defeitos ano 2002 x 2003 (Fonte Montadora de Veículo)

\begin{tabular}{|c|c|c|c|c|c|c|c|c|c|c|c|c|}
\hline VOLUME DE PROD. & 5389 & 6143 & 2868 & 1786 & 4348 & 4174 & 3541 & 4988 & 4350 & 2197 & 3384 & 3101 \\
\hline $\mathrm{N}^{\circ}$ DEFEITOS & 1645 & 2344 & 1877 & 355 & 1107 & 1317 & 1148 & 2290 & 1671 & 1099 & 877 & 960 \\
\hline $\mathrm{N}^{\mathrm{o}}$ SUJEIRAS & 609 & 831 & 590 & 161 & 463 & 588 & 371 & 870 & 495 & 311 & 256 & 233 \\
\hline$\%$ SUJEIRAS & 37 & 35 & 31 & 45 & 42 & 45 & 32 & 38 & 30 & 28 & 29 & 24 \\
\hline ÍNDICE DE DEFEITOS & 0,31 & 0,38 & 0,65 & 0,20 & 0,25 & 0,32 & 0,32 & 0,46 & 0,38 & 0,39 & 0,26 & 0,31 \\
\hline $\begin{array}{l}\text { \% CARROC. } \\
\text { ENVIADAS AO } \\
\text { RETOQUE }\end{array}$ & 13 & 13 & 16 & 8 & 11 & 12 & 12 & 16 & 15 & 17 & 8 & 8 \\
\hline MÊS & SET & OUT & NOV & DEZ & JAN & FEV & MAR & ABR & MAI & JUN & JUL & AGO \\
\hline
\end{tabular}

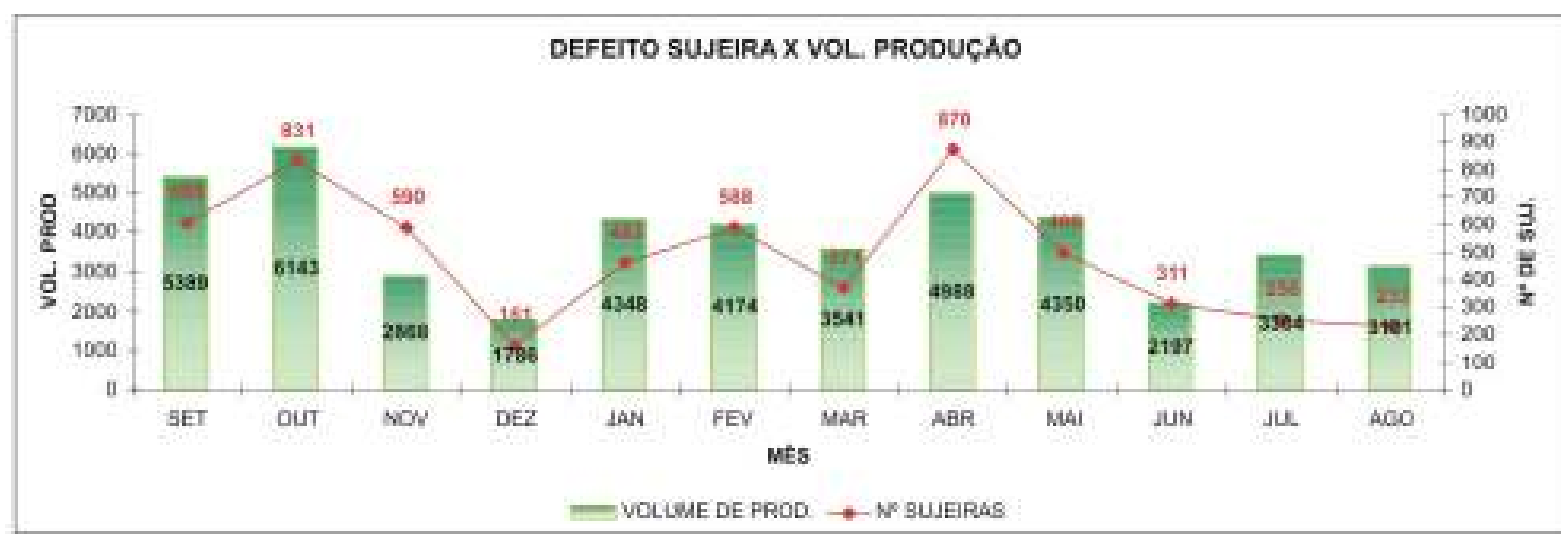

Figura 1 - Quantidade de sujeira em relação ao volume de produção (Fonte Montadora de Veículo) 
Segundo o manual de Freudenbeg (2001), uma partícula de $10 \mu \mathrm{m}$, depositada em uma carroceria, irá aumentar de tamanho de três a cinco vezes, após a pintura, ocasionando um "retrabalho" na área afetada. Para eliminar a sujeira depositada nas carrocerias, algumas empresas usam a limpeza manual utilizando pano ou ar comprimido. Estes dois tipos de limpeza não são eficientes devido à grande área que deverá ser limpa pelo operador e pelos resíduos deixados pelo pano de limpeza.

Assim, este trabalho consiste na modelagem do sistema e no desenvolvimento de uma cortina de ar automatizada, para a limpeza das carrocerias na área de pintura. Trata-se da implantação de uma estação de limpeza automática, na entrada da cabine, utilizando ar comprimido filtrado com a mesma especificação do ar de aplicação das pistolas. A modelagem do funcionamento desta cortina foi desenvolvida utilizando a linguagem de diagrama de blocos GRAFCET. A modelagem em GRAFCET permite uma análise de todas as etapas de funcionamento do sistema (SARQUIS ATTIÉ, 1998). O sistema será gerenciado por um Controlador Lógico Programável que terá como função (MAURICIO, 2002): fazer a leitura dos sinais de entrada; executar os programas de trajetória de limpeza dos veículos; acionar equipamentos e atualizar as saídas.

\section{Apresentação do sistema}

Como os veículos produzidos em uma automobilística passam por constante reestilização, todo o sistema proposto deverá ser de fácil adaptação e alta flexibilidade. Tal sistema é composto por um conjunto de sopradores de ar, que serão acionados automaticamente com a passagem do veículo pela estação de limpeza. Será formado por uma estrutura principal, que servirá de fixação para os cinco conjuntos de sopradores divididos da seguinte maneira:

- conjunto inferior lateral: limpeza das portas parte baixa, pára-lamas e saia do veículo;

- conjunto superior lateral: limpeza das portas parte alta e colunas;

- barra superior; limpeza do capô, teto e tampa traseira;

O sistema proposto, apresentado na figura 2, inicia com a identificação do veículo, para que, posteriormente, os posicionadores se desloquem de acordo com o tipo de veículo (execução da trajetória), com os sopradores ligados.

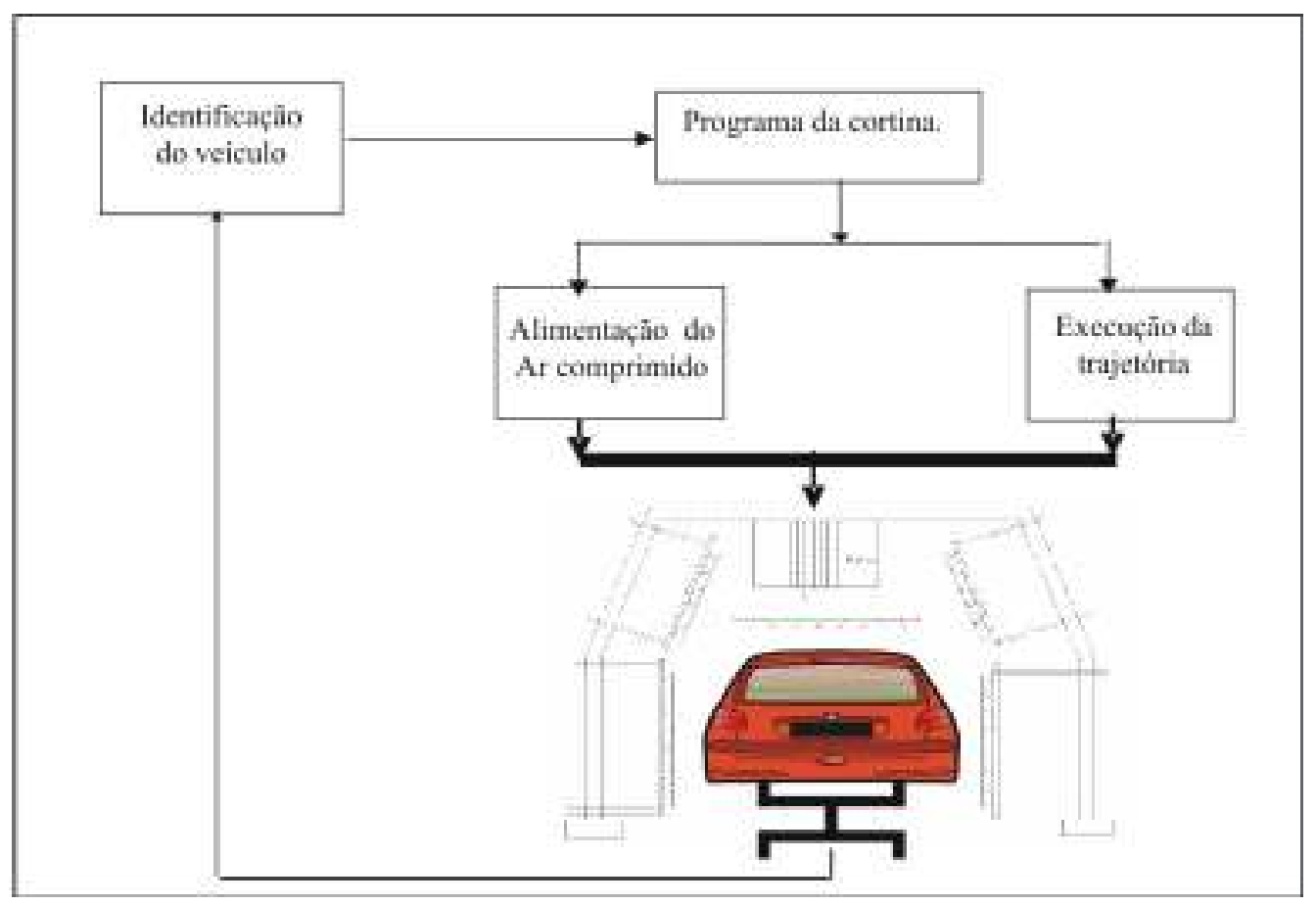

Figura 2 - Cortina de ar proposta 


\section{Método de modelagem do sistema em GRAFCET}

Esta estação de limpeza é um sistema eletro-pneumático, no qual se utiliza um controlador lógico programável e uma válvula solenóide para acionamento do ar dos sopradores. A modelagem por GRAFCET adapta-se bem a este sistema de automação, pois, com este método de modelagem pode-se verificar todas as etapas do funcionamento desta estação de trabalho. O modelo GRAFCET também é destacado pela sua utilização em todos os níveis da indústria, desde os operadores até os projetistas do sistema.

\subsection{Histórico do GRAFCET}

Em 1975, pesquisadores e gerentes industriais franceses envolvidos em complexos sistemas de controle discreto reuniram-se para comparar e avaliar os modelos e métodos para construção de sistemas de controle seqüencial. Coletaram suas experiências próprias, nas quais usavam dezessete técnicas diferentes: alguns utilizavam questionários empíricos, outros utilizavam modelos tecnológicos e outros ainda utilizavam modelos teóricos puros, derivados de "Máquinas de Estado" ou "Redes de Petri". Decidiram, então, construir um modelo customizado, chamado GRAFCET, mais fácil do que os que, até então, eram utilizados e mais adequados aos sistemas complexos e, particularmente, aos sistemas de manufatura. $\mathrm{O}$ nome derivou-se de Graph - pois o modelo tinha um fundamento gráfico e AFCET (Association Française Pour La Cybernétique Économique et Technique) - associação científica que financiou todo o trabalho. Os conceitos básicos desse sistema de controle discreto eram extremamente claros e simples: a "etapa", a "ação associada à etapa", a "transição" e a condição associada à "transição". A etapa representa um estado parcial do sistema, ao qual uma ação é realizada. Em determinado instante, uma etapa pode estar "ativa" ou "inativa". Para que exista uma transição de uma etapa para outra, é necessário que a etapa anterior esteja ativa e a condição de transição entre as duas etapas seja verdadeira (FERREIRA, 1994). A transição, que "conecta" a etapa precedente (uma ou varias etapas) à etapa seguinte (uma ou varias etapas), representa uma decisão para mudança de estado do sistema (a ação da etapa precedente é seguida pela ação da etapa seguinte). Para que uma transição seja efetuada, são necessárias duas condições (SARQUIS ATTIÉ, 1998):

- todos os passos, cuja saída está ligada à entrada da transição, estejam ativados;

- a condição associada à transição for satisfeita.

Ao ser efetuada a transição, a etapa precedente (uma ou várias etapas) torna-se inativa e a etapa seguinte (uma ou várias etapas) torna-se ativa. Conseqüentemente, a ação associada à etapa precedente deixa de ser realizada, e a associada à etapa seguinte passa a ser realizada. Na figura 3, ilustra-se um exemplo da aplicação do GRAFCET para o acionamento de um motor.

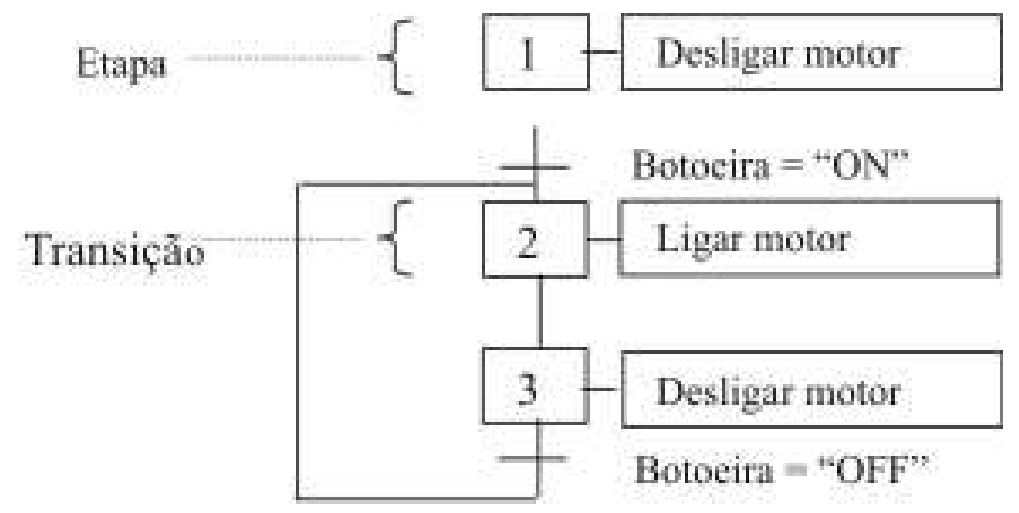

Figura 3 - Exemplo da aplicação do GRAFCET 
Em 1988, a IEC (International Eletrotechnical Commission) adotou o GRAFCET como Norma Internacional sob o nome inglês Sequencial Function Chart - SFC (Diagrama Funcional Seqüencial), com o título Preparation of Function Charts for Control Systems (Preparação de Diagramas Funcionais para Sistemas de Controle) e referência IEC 848. Com a alteração nas referências das Normas IEC, ocorrida recentemente, passou a IEC 60848.

Embora tenha sido preparada visando aplicações eletrotécnicas, a aplicação GRAFCET pode ser aplicada também a sistemas não elétricos (hidráulicos, pneumáticos ou mecânicos, por exemplo), pois descreve as funções de controle relativas a determinado sistema, independente do campo de aplicação. O método de representação proposto serve como 'ferramenta de comunicação' entre as diferentes áreas (disciplinas tecnológicas) envolvidas no desenvolvimento e utilização de sistemas automatizados. A linguagem GRAFCET permite a fácil comunicação entre os profissionais de várias áreas envolvidas no processo de automação (ROMANO e GUIMARÃES, 2001). Os fabricantes de CLP adotam o GRAFCET como linguagem de programação. O GRAFCET não substitui o Ladder na programação, mas serve para facilitar o programa, uma vez que permite uma visualização lógica de todas as etapas de funcionamento da automação.

\subsection{Diagrama funcional seqüencial}

Nas literaturas em português, o GRAFCET é conhecido pelo nome de Diagrama Funcional Seqüencial (GEORGINE, 2000). A seguir, são apresentados os elementos e as regras definidas na Norma IEC 60848. Os elementos do Diagrama Funcional Seqüencial (SFC) são:

- etapas - associadas às ações.

- transições - associadas às condições.

- ligações orientadas - conectam as etapas às transições

\subsection{Etapas}

Uma etapa é um estado no qual o comportamento do circuito de comando não se altera frente às entradas e saídas. A eficiência e a precisão de um Diagrama Funcional Seqüencial estão diretamente relacionadas à quantidade de etapas utilizadas para descrever determinado sistema. Portanto, quanto maior o número de etapas em que se puder dividi-lo, maior a eficiência da descrição de cada etapa e maior a precisão do Diagrama Funcional como um todo. A simbologia utilizada para representar uma etapa é mostrada na Figura 4.a , na qual não é definida uma relação de tamanho entre os lados do retângulo, sendo recomendada a igualdade (quadrado). Assim, as etapas são referenciadas por meio de caracteres alfanuméricos (em substituição ao asterisco, conforme apresentado na Figura 4.b) de forma arbitrária, ou seja, não há necessidade de utilização seqüencial dos caracteres, e nem de respeito à ordem numérica (crescente ou decrescente).

\subsection{Etapa ativa e etapa inativa}

Em determinado instante, uma etapa pode estar ativa ou inativa.Uma etapa é ativa até que a sua receptividade seguinte seja verdadeira, sendo que a situação de um sistema é determinada pelo conjunto de etapas ativas naquele momento (BITTAR, 1993).

\subsection{Etapa inicial}

A etapa inicial é aquela que se torna ativa logo após o início do funcionamento do GRAFCET. Podem existir tantas etapas iniciais quantas se fizerem necessárias, sendo que todas serão ativadas, simultaneamente, no início do controle do sistema. A simbologia, utilizada para representar uma etapa inicial, é exibida na Figura 4.c. 


\subsection{Indicação do estado de uma etapa}

A representação do estado de uma etapa pode ser feita pelos valores lógicos « 0 » (inativa) ou "1" (ativa) de uma variável binária "X". Por exemplo, X2 - 0 (etapa 2 inativa).

Para indicação das etapas ativas em determinado momento, no Diagrama Funcional, utiliza-se um ponto $(\bullet)$, localizado na parte inferior interna aos símbolos correspondentes, como apresentado na Figura 4.d.

Este ponto não pertence à simbologia da etapa, sendo utilizado apenas para análise e/ou apresentação do Diagrama Funcional Seqüencial.

\subsection{Ações associadas às etapas}

As ações são executadas somente se a etapa à qual estão associadas estiver ativa; caso contrário, são ignoradas. Enquanto a etapa estiver ativa, as ações podem ser iniciadas, continuadas ou finalizadas. Quando a etapa for desativada, as ações podem ser continuadas ou finalizadas, conforme a definição utilizada.

A ação, associada à etapa, é definida por declaração textual ou simbólica, inserida em um retângulo, de qualquer tamanho, conectado ao lado direito da etapa correspondente, conforme indica a Figura 4.e.

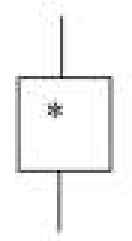

(a)

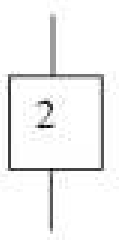

(b)

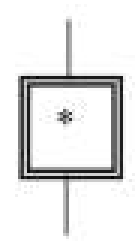

(c)

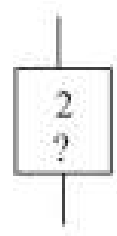

(d)

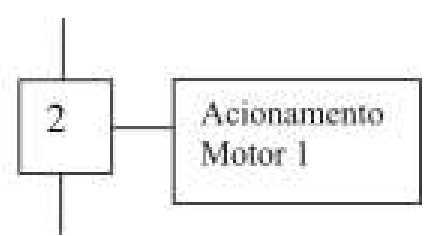

(e)

Figura 4 - Representação dos elementos

\subsection{Representação gráfica do funcionamento da cortina em Grafcet}

Através da descrição do funcionamento da cortina em GRAFCET, verifica-se, de uma maneira geral, todas as etapas e transições a serem executadas durante a entrada do veículo na estação de limpeza e a saída, após a sua limpeza, a ser realizada. Observa-se também o seu funcionamento, tanto no modo manual como no automático.

A descrição funcional do equipamento, além de mostrar com clareza quais os controles a serem implementados, permite ainda que seja desenvolvido todo o conceito de funcionamento do equipamento (ROMANO e GUIMARÃES, 2001).

A figura 5 apresenta o fluxograma para o funcionamento da cortina, desde a identificação do veículo até a passagem total do veículo pela estação de limpeza. 


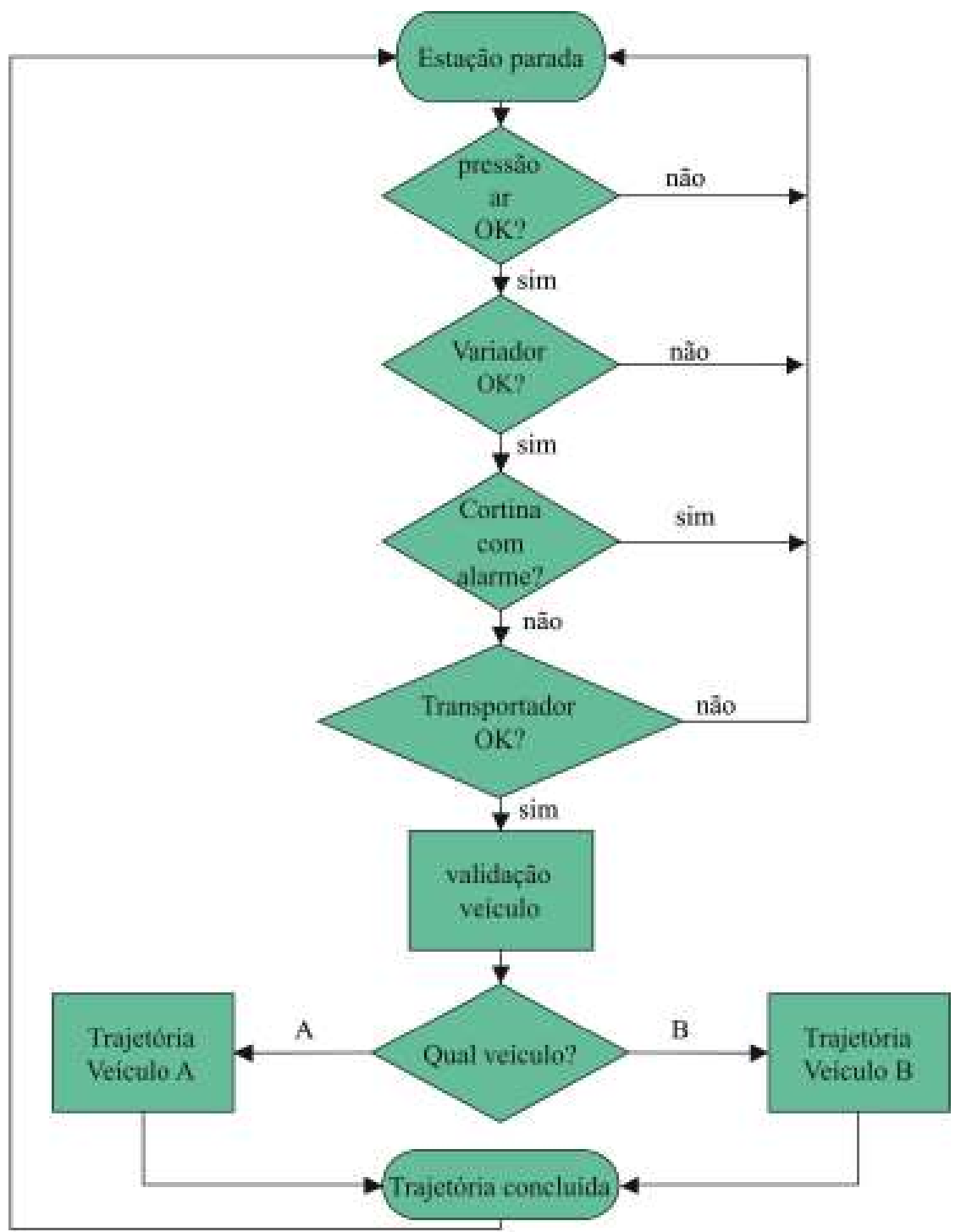

Figura 5 - Fluxograma do sistema

\subsection{Modelagem do sistema de identificação do veículo em GRAFCET}

A Figura 6 (etapas de 0 a 4) apresenta o modelo GRAFCET para a descrição da identificação do veículo no sistema. Os modelos em GRAFCET apresentados a seguir foram desenvolvidos utilizando o software PL7 PRO da Schineider. 


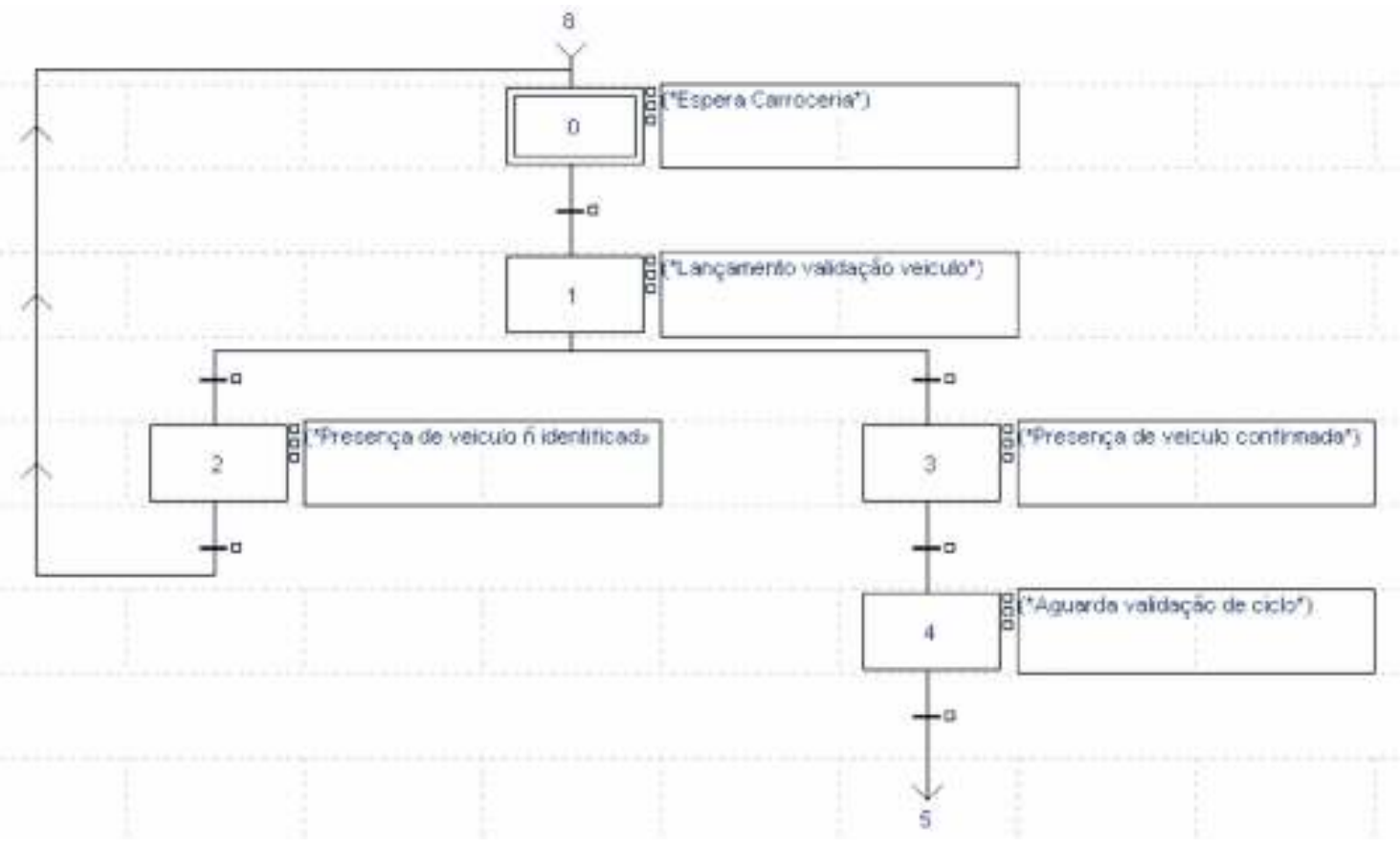

Figura 6 - GRAFCET do sistema de identificação

3.10 Modelagem do sistema execução da trajetória do veículo em GRAFCET, apresentada nas etapas de 6 a 9 (Figura 7)

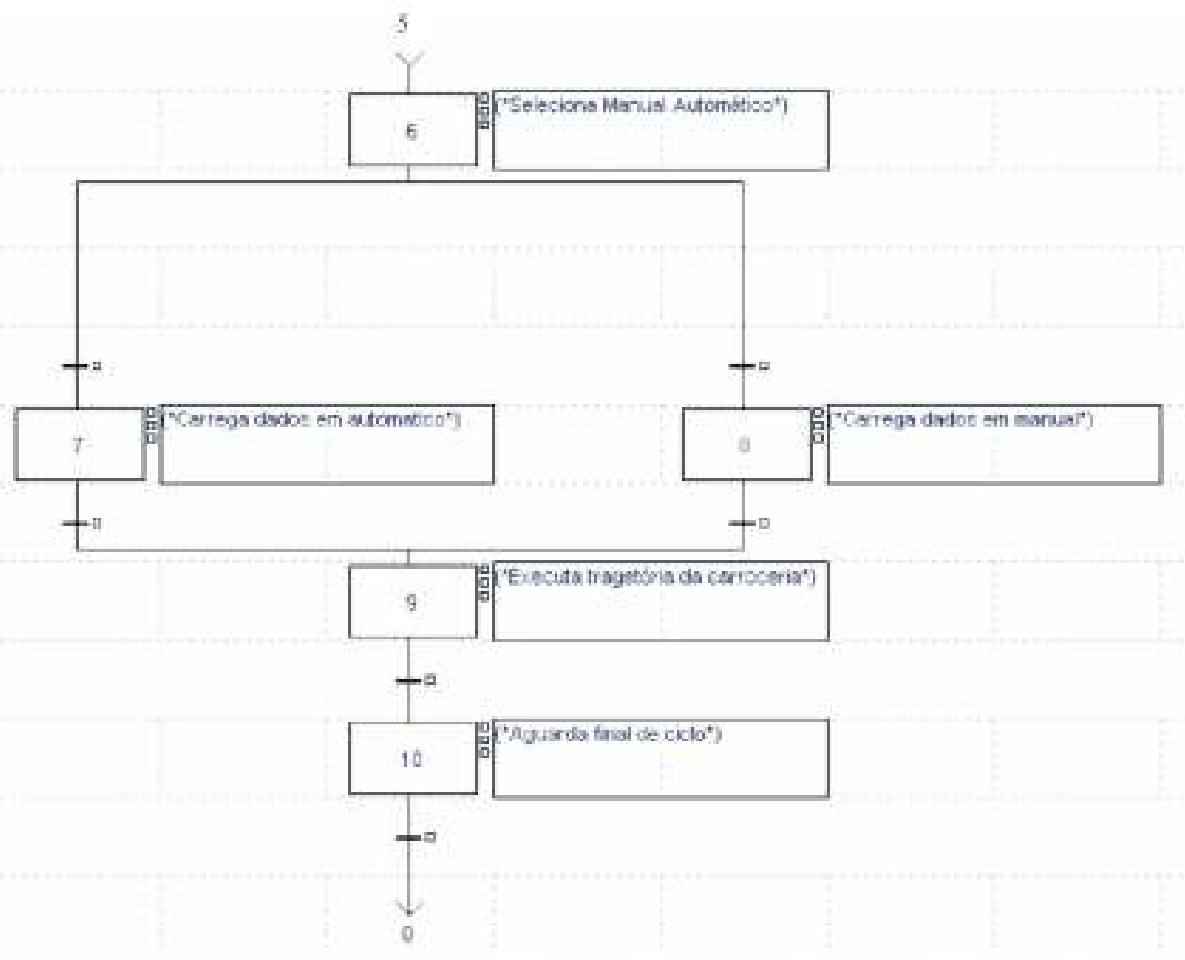

Figura 7 - GRAFCET do sistema de execução da trajetória 


\subsection{Modelagem completa de funcionamento da cortina em GRAFCET, é representado através das etapas de 0 a 10 (Figura 8)}

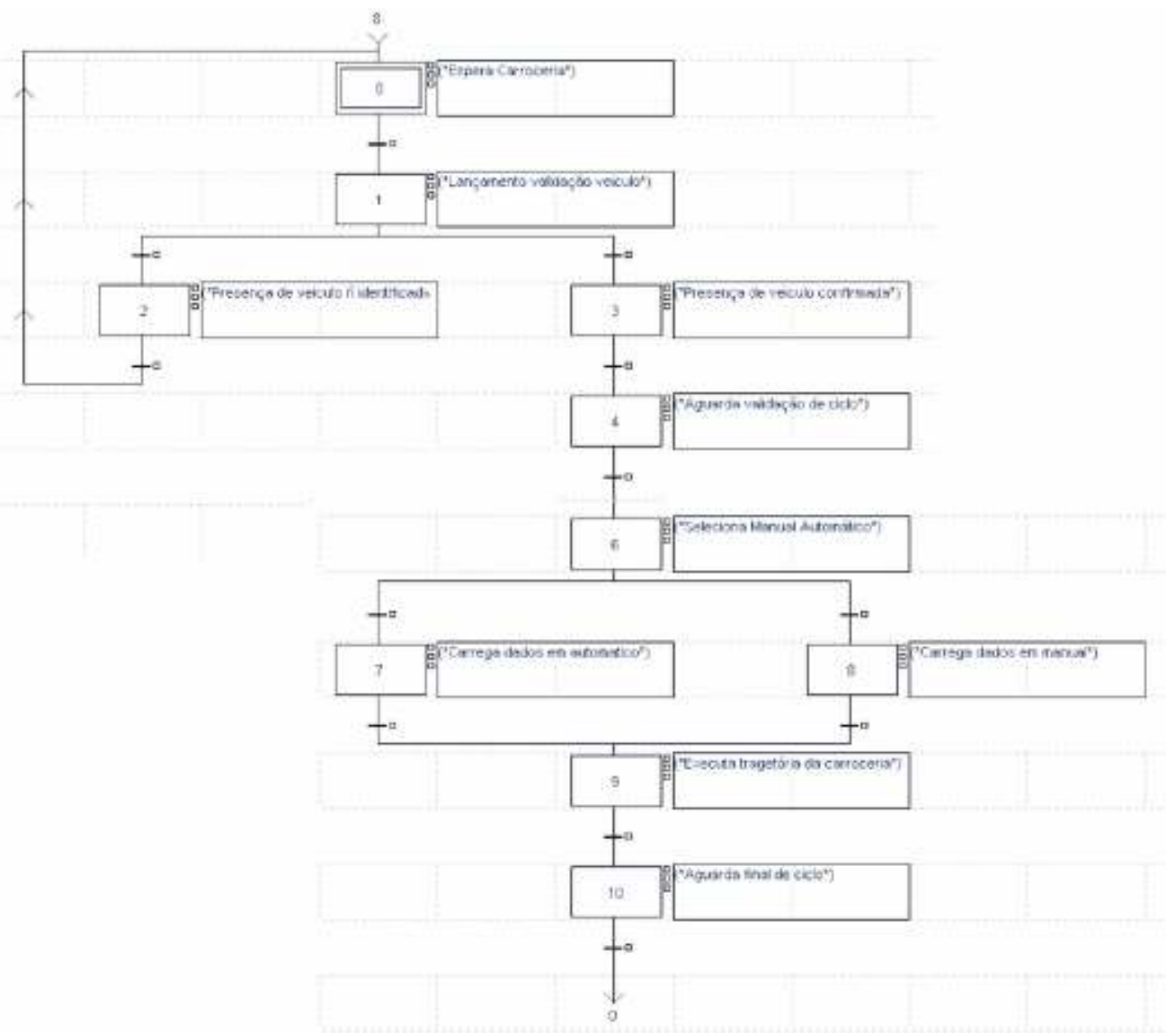

Figura 8 - GRAFCET completo do sistema de execução da trajetória

\section{Resultados - Ensaios realizados}

Com a montagem de placas protótipos no automóvel, observou-se que é possível diminuir em 40,7\% a sujeira de uma superfície através de uma limpeza bem realizada utilizando cortina de ar. As placas foram montadas na lateral do veículo para análise da influência do ar exterior na sujeira das carrocerias. Estas placas protótipos foram limpas e pintadas em base e verniz. Foi escolhida a cor preta, por se tratar da cor que apresenta maior sujeira. As placas foram montadas na carroceria, como mostra a Figura 9, na área de saída do lixamento do primer. As placas seguiram o mesmo percurso que o veículo dentro do prédio da pintura até a entrada da cabine. Dentro da cabine, a placa, localizada no lado esquerdo da carroceria, foi limpa (placa ${ }^{\circ} 1$ ) e a localizada no lado direito, não (placa $n^{\circ} 2$ ). Após ser pintada em base de verniz e seca na estufa, a placa foi enviada para o laboratório para ser realizado o ensaio metalográfico. Neste ensaio, utilizou-se para medição e identificação das impurezas o microscópio ótico Olympus BX 60 ampliação de $100 X$. 


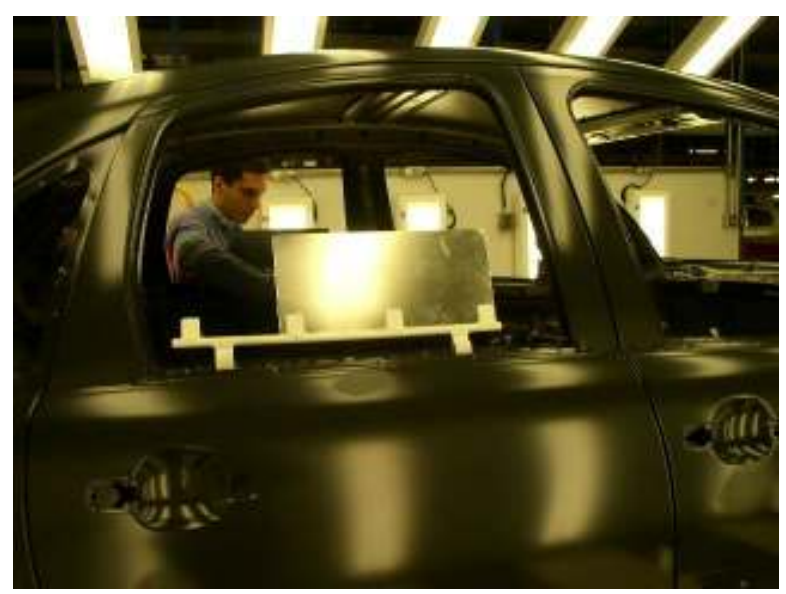

Figura 9 - Montagem da placa na carroceria

\subsection{Descrição das partículas encontradas nas placas protótipos}

As placas pintadas à base de verniz apresentaram impurezas com dimensões e formas variadas, onde considerou-se somente partículas acima e 5,0 $\mu \mathrm{m}$, tais como:

- ponto preto, figura 10.a;

- partícula sólida em forma de círculo, figura 10.b;

- fiapo, figura 10.c;

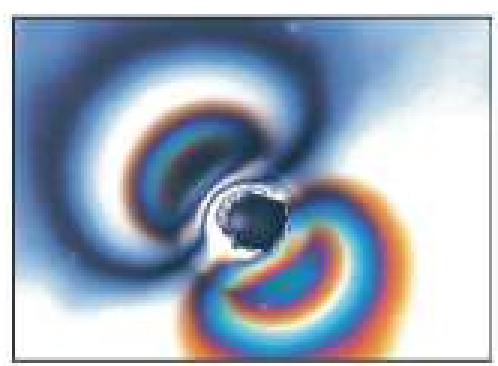

(a)

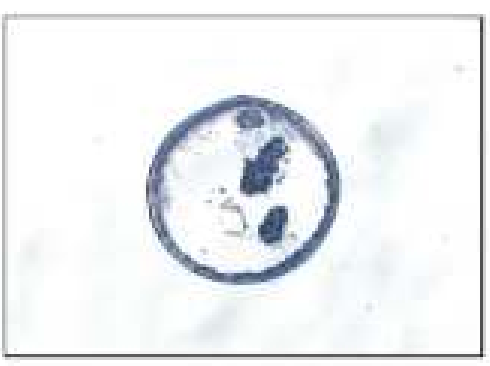

(b)

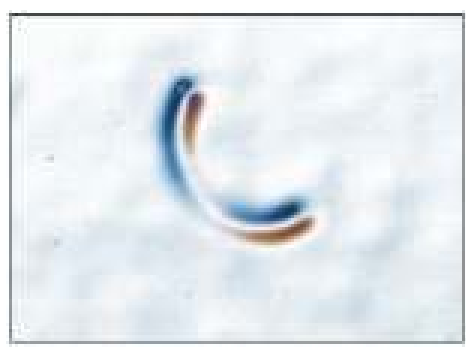

(c)

Figura 10 - Tipos de partículas contidas na placa

\subsection{Análise dos resultados encontrados}

Com uma limpeza eficiente, como demonstrado no ensaio com as placas, poderemos ter um ganho real com relação à sujeira da superfície.

Na placa limpa, foram encontradas 16 partículas acima de $5 \mu \mathrm{m}$. Na placa sem limpar, foram encontradas 27 partículas acima de $5 \mu \mathrm{m}$.

Com base nestes dados, projeta-se o seguinte ganho na limpeza com a utilização de um sistema de limpeza eficiente;

Ganho de Limpeza $=40,7 \%$ 


\section{Análises e conclusões}

Com a implantação deste sistema de limpeza automática das carrocerias na área de pintura, é possível diminuir o número de impurezas encontradas nas superfícies dos automóveis, melhorando a qualidade da pintura do veículo, e reduzir os custos com retrabalhos na pintura.

A modelagem do sistema em GRAFCET permite a visualização de uma maneira global de todo o sistema de funcionamento, na fase de estudos. Este modelo empregado nos permite a descrição funcional do equipamento e a possibilidade de transformar facilmente o modelo GRAFCET em outras linguagens de programação, diagramas pneumáticos, elétricos e diagrama ladder.

Este sistema permite ainda uma fácil adaptação para diferentes superfícies (modelos de automóveis), uma vez que se trabalha com uma linguagem de fácil programação.

Os resultados da eficiência deste sistema foram comprovados através de uma simulação do processo de limpeza em placas. Posteriormente, as placas de ensaio foram enviadas para um laboratório para levantar o número de partículas que permaneceram na superfície após a limpeza.

\section{Referências}

BITTAR, Rita. A Utilização do GRAFCET como Ferramenta na Automação Industrial. 1993. Dissertação Mestrado. Universidade Estadual de Campinas, São Paulo: UNICAMP.

FERREIRA, Jorge Augusto Fernandes. Virtualização de Autômatos Programáveis. 1994. 153 f. Dissertação (Mestrado em Engenharia. Eletrônica e Telecomunicações). Universidade de Aveiro, Portugal.

FREUDENBERG. Filtração de Ar nas Cabines e Secadores em Plantas de Pintura. In: Seminário Técnico, 2001, Jacareí: The Freudenberg Nonwovens Group, 2001.

GEORGINE, Marcelo. Automação Aplicada Descrição e Implementação de Sistemas Seqüências com PLCs, Érica, São Paulo, 2000, p.22.

MAURICIO, S. P. Interface Homem-Máquina para Supervisão de um CLP em Controle de Processos Através da WWW. Dissertação de Mestrado, Universidade de São Paulo, 2002.

ROMANO, V. F.; GUIMARÃES, P. R. A. Projeto de Alimentador Pneumático para Automação de Processo de Alimentação de Chapas em Prensas CNC. In: V SBAI - Simpósio Brasileiro de Automação Inteligente 2001. Canela: SBAI, 2001.

SARQUIS ATTIÉ, Sérgio. Automação Hidráulica e Pneumática - Empregando a Teoria de Sistemas a Eventos Discretos. 212 f. Dissertação (Mestrado em Engenharia Mecânica) - Universidade Federal de Santa Catarina, Florianópolis: 1998. 